\title{
UMA LEITURA DO CONTO UM MÉDICO RURAL, DE FRANZ KAFKA, À LUZ DO INCONSCIENTE FREUDIANO: ENTRE DAS UNHEIMLICHE E O GROTESCO
}

\author{
Gustavo Figliolo (Letras Estrangeiras Modernas - UEL)
}

\section{RESUMO}

O conceito de Unheimliche foi publicado por Sigmund Freud em 1919 e traduzido ao português como "O Estranho" (Das Unheimliche) e indica de um modo geral uma alegoria do retorno do recalcado. A estranheza provocada deriva do fato de que o evento que vem à tona não se trata de uma coisa externa, algo exterior ao indivíduo, mas, de algo estranhamente familiar, "impressão de estranheza (que) surge na vida cotidiana e na criação estética quando certos complexos infantis recalcados são abruptamente despertados" (ROUDINESCO; PLON, 1997). Por outro lado, a categoria do grotesco implica, de maneira generalizada, a criação de universos fantásticos, o apelo à fantasia e ao onírico, o bizarro e outras formas estranhas de representação da realidade. No conto Um Médico Rural, de Franz Kafka, podem ser observadas essas características do estranho e do grotesco veiculados pelo inconsciente que desvenda a angústia do sujeito quando é destruída nele qualquer faculdade de desejar. Essa é a leitura que este artigo propõe-se examinar.

Palavras-chave: unheimliche, grotesco, psicanálise.

Sigmund Freud começa seu texto $O$ Estranho (Das Unheimliche) propondo uma aproximação ao termo Unheimliche como significando uma impressão assustadora, que causa angústia e horror, mas aborda a tentativa de explicação seguindo dois caminhos. No primeiro, ele faz uma investigação linguístico-semântica do vocábulo tentando verificar o sentido que a palavra foi adquirindo ao longo da história, desde a acepção grega até a modernidade; assim o unheimlich (estranho, assustador, sobrenatural) chega a essa conotação a partir de heimlich (familiar, doméstico, íntimo), conforme Freud:

O que mais nos interessa nesse longo excerto é descobrir que entre os seus diferentes matizes de significado a palavra 'heimlich" exibe um que é idêntico ao seu oposto, 'unheimlich'. Assim, o que é heimlich vem a ser unheimlich. [...] Em geral, somos lembrados de que a palavra 'heimlich' não deixa de ser ambígua, mas pertence a dois conjuntos de ideias que, sem serem contraditórias, ainda assim são muito diferentes: por um lado significa o que é familiar e agradável e, por outro, o que está oculto e se mantém fora da vista. 'Unheimlich' é habitualmente usado, conforme aprendemos, apenas como o contrário do primeiro significado de 'heimlich', e não do segundo. [...] Por outro lado, percebemos que Schelling diz algo que dá um novo esclarecimento ao conceito do Unheimlich, para o qual certamente não estávamos preparados. Segundo Schelling, unheimlich é tudo o que deveria ter permanecido secreto e oculto mas veio à luz. (FREUD, [1919] 2006, p. 279 


\section{SEMINÁRIO DE PESQUISA EM CIÊNCIAS HUMANAS - SEPECH \\ Humanidades, Estado e desafios didático-científicos \\ Londrina, 27 a 29 de julho de 2016}

Em segundo lugar, propõe para o conceito tudo aquilo que desperta no ser humano o sentimento de estranho, seja em pessoas, coisas, situações, impressões etc. Diferentemente do que se poderia deduzir, que o estranho teria correspondência com o desconhecido, o estranho para Freud é provocado por situações familiares, vividas e conhecida há já muito tempo. Ele utiliza a modo de exemplificação o conto $O$ Homem de Areia, de Ernst Theodor Amadeus Hoffmann, escritor do período romântico alemão. No conto, o jovem Natanael escreve uma carta a seu amigo Lotário contando que recebeu a visita de um vendedor de barômetros e se assustou de tal modo que o expulsou da casa. O susto de Natanael se origina em uma lembrança de infância, em que as crianças eram postas na cama pois o homem de areia estava para chegar. A babá dizia a ele que às crianças que não fossem dormir cedo, o homem de areia jogava areia em seus olhos fazendo com que estes saltassem e os colocava em um saco para levá-los como alimento a seus filhos na lua. Para descobrir mais sobre o homem de areia, Natanael se esconde no escritório do seu pai à espera de um homem que iria visitá-lo uma noite. Reconhece nele o advogado da família, Copellius, mas é descoberto e o ameaçam (seu pai e Copellius) com arrancar seus olhos. Ele associará anos mais tarde a Cópolla, o vendedor de barômetros, com Copellius, originando o susto que fez com que ele escrevesse para o seu amigo. No plano psicanalítico, o medo a perder os olhos consiste em uma angústia infantil que com frequência persiste nos adultos e que não é mais que um substitutivo do medo da castração. Nesse sentido Freud também se servirá da história de Édipo que se "castra" simbolicamente arrancando os seus olhos. Assim, os olhos estão associados aos genitais masculinos, o pênis mais precisamente, e o medo a sua castração vai repercutir também na possibilidade de perda de outros órgãos. Freud ([1918] 2006, p.248) comenta que "a ameaça de ser castrado excita de modo especial uma emoção particularmente violenta e obscura, e que é essa emoção que dá, antes de mais nada, intenso colorido de perder outros órgãos". O episódio da infância que originou o medo de perder os olhos (ser castrado) de Natanael é (re)ativado na figura do vendedor de barômetros que bate à porta de sua casa, originando angústia e horror: o estranho (o evento que causa estranheza) é em realidade muito familiar, estava em Natanael adormecido de maneira inconsciente e conseguiu deslocar-se para a consciência em circunstâncias específicas. Dessa maneira, e conforme (ROUDINESCO; PLON, 1997, p. 383), origina-se uma "impressão de estranheza (que) surge na vida cotidiana e na criação estética quando certos complexos infantis recalcados são abruptamente despertados" Citando a Lacan, ainda os autores comentam que:

Apoiando-se no Unheimlich, ele (Lacan) efetivamente mostrou que a angústia surge quando o sujeito é confrontado com a "falta da falta", ou seja, com uma alteridade onipotente (pesadelo, duplo alienante, estranheza inquietante) que o invade a ponto de destruir nele qualquer faculdade de desejar. (ROUDINESCO; PLON, 1997, p. 383).

Assim, Freud considera que a repressão produz angústia, e em alguns casos uma determinada angústia é algo reprimido que retorna causando-a pelo caráter estranho do acontecimento: causa angústia por retornar do reprimido. Dessa maneira, isso explica a passagem de Heimlich a Unheimlich, alguma coisa familiar antigamente que se torna alheia pelo processo de repressão. Aqui cobra relevo a afirmação de Schelling de que 


\section{SEMINÁRIO DE PESQUISA EM CIÊNCIAS HUMANAS - SEPECH \\ Humanidades, Estado e desafios didático-científicos \\ Londrina, 27 a 29 de julho de 2016}

"unheimlich é tudo o que deveria ter permanecido secreto e oculto mas veio à luz" (SCHELLING apud FREUD, [1919] 2006, p. 282).

Embora Freud considere que o estranho vem a ser algo familiar que sofreu repressão e retorna, não é possível inverter a afirmação e dizer que tudo o que retorna do reprimido é estranho (ou causa estranheza). São necessárias outras condições para tal, e Freud começa apontando a necessidade de perigo, fazendo alusão a angústias infantis que persistem em determinadas situações como diante da calma, da solidão, da escuridão, em que o sujeito se encontra "sozinho consigo mesmo", por assim dizê-lo. Dessa maneira, o estranho acontece quando complexos infantis reprimidos são reanimados por uma impressão.

Conforme sugerimos no título do artigo, o retorno do recalcado à consciência que causa o estranhamento, o medo e a angústia conserva alguma analogia com a estética (vamos assim considerá-la) do grotesco. A arte grotesca, assim como a Unheimlich causa no sujeito que com ela se depara sensações similares. As Cabeças Grotescas, de Leonardo da Vinci ou as pinturas de Hyerônimus Bosch, para mencionar somente dois artistas extraordinários, são exemplos magníficos de arte grotesca, que causam uma série de sensações que vão do estranhamento à perplexidade, passando pelo desconforto e a inquietação. Em $O$ Grotesco, de Wolfgang Kayser, uma das principais obras de referência teórica sobre o assunto, o autor comenta a respeito da origem da palavra:

A "grotesca", isto é, o grotesco, e os vocábulos correspondentes em outras línguas são empréstimos tomados do italiano. La grotesca e grotesco, como derivações de grota (gruta), foram palavras cunhadas para designar determinada espécie de ornamentação, encontrada em fins do século $\mathrm{XV}$, no decurso de escavações feitas primeiro em Roma e depois em outras regiões da Itália. O que se descobriu foi uma espécie até então desconhecida de pintura ornamental antiga. Logo se constatou que não era autóctone romana, mas que chegara a Roma como nova moda, relativamente tarde, por volta da época da transição. ${ }^{1}$ (KAYSER, 2013, p. 17-18).

O derivativo da palavra, de "gruta", sugere aquilo que está escondido e vem à luz por meio de escavações, coincidindo em sua essência com o processo de Unheimlich freudiano. O que nos é dado a conhecer de maneira imprevista e intempestiva, descobrimento do qual não fazíamos ideia que subjazia nossa consciência (no caso da Unheimlich), assim como se revela um tesouro arqueológico dentro de uma gruta. Mas, além da imprevisibilidade da descoberta, é necessário, como comentado anteriormente, que a mesma cause certo estranhamento. Comenta Kayser:

O grotesco é uma estrutura. Poderíamos designar sua natureza como uma expressão, que já se nos insinuou com bastante frequência: $o$ grotesco é o mundo alheado ${ }^{2}$ (tornado estranho). [...] Para pertencer a ele, é preciso que aquilo que nos era conhecido e familiar se revele, de repente, estranho e sinistro. (KAYSER, 2013, p. 159).

\footnotetext{
${ }^{1}$ Passagem da Roma Imperial para o início da Idade Média, com a divisão do Império Romano em oriental e ocidental.

${ }^{2}$ Em itálico no original.
} 


\section{SEMINÁRIO DE PESQUISA EM CIÊNCIAS HUMANAS - SEPECH \\ Humanidades, Estado e desafios didático-científicos \\ Londrina, 27 a 29 de julho de 2016}

Posta a relação de semelhança, verdadeira analogia entre a Unheimlich e o grotesco, tentaremos exemplificar a questão com a análise do conto Um Médico Rural, de Franz Kafka.

$\mathrm{Na}$ linha de seus relatos e digno de merecer o adjetivo "kafkiano", a história do conto acontece como um verdadeiro pesadelo: há uma estranheza incompreensível, mas, ao mesmo tempo, necessária para a estrutura do relato. Um médico precisa sair na metade da noite para atender uma solicitação urgente feita por um homem doente que mora em uma vila afastada a alguns quilômetros, durante um terrível tempo em condições de nevasca. Os cavalos que tinha para seu coche morreram na noite passada, mas (e aqui aparece o primeiro elemento onírico/estranho), alguém surge de uma pocilga que ele não usava há anos e não somente lhe empresta dois cavalos, mas se oferece como condutor:

Bati com o pé na frágil porta da pocilga que já não era usada fazia anos. Ela se abriu, foi e voltou estalando nos gonzos. Veio de dentro um bafo quente e um cheiro como que de cavalos. Uma tosca lanterna de curral oscilava pendente de uma corda. Um homem acocorado no cômodo baixo mostrou o rosto aberto e de olhos azuis. [...] Olá irmão, olá irmã! - bradou o cavalariço e dois cavalos, possantes animais de flancos fortes, as pernas coladas ao corpo, baixando as cabeças bem formadas como se fossem camelos, saíram um atrás do outro, impelidos só pela força dos movimentos do tronco, através da abertura da porta que eles ocupavam por completo. (KAFKA, 2015, p. 13-14).

O cavalariço, ser estranho que surge das profundezas de uma pocilga (note-se a semelhança com uma caverna), põe como condição para emprestar os cavalos ficar com a criada do médico, ao que este se nega; ela se esconde na casa e os homens partem. Sem solução de continuidade, isto é, sem interrupção, o narrador nos conta nas linhas seguintes que os homens chegaram a destino:

Bate palmas; o veículo é arrastado como madeira na correnteza; ainda ouço quando a porta de minha cassa estrala e se espatifa ao assalto do cavalariço, depois olhos e ouvidos são tomados por um zunido que penetra uniformemente todos meus sentidos. ${ }^{3}$ Mas por um instante apenas, pois como se diante do portão do pátio se abrisse o pátio do meu doente, já estou lá; os cavalos estão quietos; a neve parou de cair. (KAFKA, 2015, p. 15).

Um zunido penetra os sentidos do médico e o estranho se faz presente: como nos sonhos, o tempo desaparece, a continuidade se dissolve. O médico, então, passa a ver o paciente, que aparentemente está são; não encontra nada nele, mas ele cochicha-lhe no ouvido: “- Doutor, deixe-me morrer" (KAFKA, 2015, p. 16). A situação é mais bizarra e amedrontadora com a presença das cabeças dos cavalos, cada uma enfiada em duas janelas que o quarto possui:

Esses cavalos que agora de algum modo afrouxaram as correias; que não sei como escancararam as janelas pelo lado de fora; que enfiam

\footnotetext{
${ }^{3}$ Itálico nosso.
} 


\section{SEMINÁRIO DE PESQUISA EM CIÊNCIAS HUMANAS - SEPECH \\ Humanidades, Estado e desafios didático-científicos \\ Londrina, 27 a 29 de julho de 2016}

cada qual a cabeça por uma janela e sem se perturbarem com a gritaria da família contemplam o doente. (KAFKA, 2015, p. 16).

Os cavalos olham diretamente o doente, produzindo mais estranheza na situação toda. A narração se torna mais caótica quando o médico, em um monólogo interior, se pergunta: "o jovem pode estar com a razão e também eu quero morrer. O que estou fazendo aqui neste inverno interminável?" (KAFKA, 2015, p. 17). Aqui se manifesta a "falta da falta" de que falava Lacan, a estranheza inquietante produzida pela falta de desejo: o sujeito não sabe o que quer. Mas, o médico não tem muito tempo para devaneios, pois descobre o que realmente tortura o paciente, quando os dois cavalos relincham chamando a atenção dele, o doente tem uma ferida supurante e cheia de minhocas:

No seu lado direito, na região dos quadris, abriu-se uma ferida grande como a palma da mão. Cor-de-rosa, em vários matizes, escura no fundo, tornando-se clara nas bordas, delicadamente granulada, com o sangue coagulado de forma irregular, aberta como a boca de uma mina à luz do dia. Assim parece à distância. De perto mostra mais uma complicação. Quem pode olhar para isso sem dar um leve assobio? Vermes da grossura e comprimento do meu dedo mínimo, rosados por natureza e além disso salpicados de sangue, reviram-se para a luz, presos no interior da ferida, com cabecinhas brancas e muitas perninhas. (KAFKA, 2015, p.18).

A passagem revela, como nenhuma outra no conto, o ápice do grotesco; a descrição é ornada com profusa adjetivação que ressalta o caráter bizarro e enjoativo do quadro; trata-se da ornamentação de uma ferida que marca o ponto culminante do sentir do doente, que pergunta ao médico: "Você vai me salvar?" (KAFKA, 2015, p. 19). O mundo irreal, onírico do relato junto com a atmosfera de pesadelo dilui, de alguma maneira, a capacidade de assombro do leitor, na medida em que o doente aceita seu destino. Não sabemos se morre (a narrativa não deixa claro isso), mas em determinado momento o médico chega à conclusão de que é ele quem tem de se salvar, e sai quase fugindo do lugar, com o coro das pessoas que o atormentam com cânticos estranhos. Em determinado momento ele fica sem roupas e, embora consiga aparelhar os cavalos e subir no carro, estes vão lentamente, como nos sonhos quando se tenta fugir de algo e a velocidade não responde. O médico, impotente, lamenta-se:

Assim nunca vou chegar em casa; meu próspero consultório está perdido [...] em minha casa se enfurece o asqueroso cavalariço; Rosa é sua vítima, mas não quero pensar nisso. $\mathrm{Nu}$, exposto á geada desta época desafortunada, com um carro terrestre e cavalos não-terrenos, vou - um velho - vagando. [...] Fui enganado! Enganado! Uma vez atendido o alarme falso da sineta noturna - não há mais o que remediar, nunca mais.

O fim reforça o sentido estranho do relato. Considerando a inverossímil ruptura cronológica e o teor dos acontecimentos, podemos inferir que estamos diante de um sonho, ou um pesadelo, melhor. Com base nas categorias de Unheimlich, de Sigmund Freud e sua analogia com o grotesco na arte, temos alguns elementos para supor que há 


\section{SEMINÁRIO DE PESQUISA EM CIÊNCIAS HUMANAS - SEPECH \\ Humanidades, Estado e desafios didático-científicos \\ Londrina, 27 a 29 de julho de 2016}

sempre algo estranho, que escapa a nossa compreensão e que acomete desde lugares que desconhecemos, causando-nos angústia e temor. Kayser o coloca da seguinte maneira:

Diante destas definições logo nos vêm à lembrança os traços essenciais do grotesco: despedaçar a realidade, inventar o mais inverossímil, reunir à força coisas distintas, alhear o existente. (KAYSER, 2013, p. 135).

Franz Kafka faz um verdadeiro collage de coisas distintas: um cavalariço que aparece do nada em uma noite gelada de inverno, embaixo da neve, com dois cavalos essenciais para uma viagem; um doente que aparenta não ter nada, mas que descobre-se ter uma ferida imunda; cavalos que marcam, com suas cabeças penduradas nas janelas, olhando a cena e relinchando em momentos chave, o proceder do médico até achar a ferida; as pessoas do lugar que gritam coisas de ordem contra o médico; o médico que de repente fica nu e foge voltando para sua casa: eis o acumulo de situações estranhas e bizarras que pontuam o relato kafkiano. Esta mescla improvável, juntamente com as descrições grotescas que a acompanham, revelam outra face da narrativa, que diz respeito ao seu campo da criação estética. Com efeito, a questão estética esteve pautada, historicamente, como a diferença entre o belo e o feio. Assim aparece nas concepções de Inmanuel Kant (2012, p.168), para quem "a arte bela mostra sua preeminência precisamente no fato de que ela descreve belamente as coisas que na natureza seriam feias e desaprazíveis"; e de Wilhelm Hegel (2001, p. 172), que afirma que "para exprimir a beleza espiritual, o artista fará bem em evitar a fealdade das formas exteriores, ou então deverá saber transfigurá-la pela força da alma que nelas se refletirá, o que não quer dizer que poderá sempre dispensar-se de pintar o feio". Embora os autores considerem a categoria do belo como atrelada aos sentidos e ao gosto, isto é, difícil de ser apreendida absoluta e univocamente, há em suas ideias uma referência à visão de belo como se opondo a feio.

Esta visão maniqueísta tenta ser desconstruída por Theodor Adorno (1970) em sua Teoria Estética, quem considera que o belo precisa ser desfragmentado em sua categorização fechada (belo versus feio) e revisto à luz das necessidades estéticas de cada obra de arte em particular, em contraposição com as teorias históricas. Dessa maneira, a pintura Saturno devorando um de seus filhos, de Rubens, deveria ser considerada como bela, embora observá-la provoque certa repulsão: o artista capta aí o flagrante do mito, que se alimenta de seu próprio horror para perpetuar-se. Assim também Freud considera que o belo não deveria se restringir puramente às coisas "harmoniosas" ou "simetricamente perfeitas", mas que ele pode estar contido em elementos perturbadores ou estranhos. Diz o autor:

Nada em absoluto encontra-se a respeito deste assunto em extensos tratados de estética, que em geral preferem preocupar-se com o que é belo, atraente e sublime - isto é, com sentimentos de natureza positiva e com as circunstâncias e os objetivos que os trazem à tona, mais do que com os sentimentos opostos, de repulsa e aflição. (FREUD, [1919] 2006, p. 238).

Já em 1919 Freud chamava a atenção para a possibilidade de existência do belo em "sentimentos de repulsa e aflição", provavelmente porque o pai da psicanálise sabia, 


\section{SEMINÁRIO DE PESQUISA EM CIÊNCIAS HUMANAS - SEPECH \\ Humanidades, Estado e desafios didático-científicos \\ Londrina, 27 a 29 de julho de 2016}

ou intuía que tanto Eros quanto Tanatos existem no sujeito: os deuses do amor e da morte em luta constante por meio das pulsões que habitam o indivíduo.

O conto de Franz Kafka Um Médico Rural mostra como das Unheimlich pode surgir na consciência do homem, de maneira imprevista, de maneira grotesca, de maneira aflitiva. "A angústia tem inegável relação com a expectativa: é angústia por algo. Tem uma qualidade de indefinição e falta de objeto", postulou Freud ([1926] 2006, p.98). Os sonhos como manifestações do inconsciente revelam muito do que permanece escondido em nós, mas que estão à espreita de vir à tona causando estranheza e angústia porque podem destruir a faculdade de desejar, uma vez que às vezes constitui um retorno do recalcado ilegível que reafirma uma insatisfação. Essa alteridade onipotente de que fala Lacan e que produz insatisfação pela falta do objeto de desejo faz o médico afirmar, nas últimas linhas do conto, que "não há mais o que remediar, nunca mais".

\section{REFERÊNCIAS BIBLIOGRÁFICAS}

ADORNO, Theodor. Teoria Estética. Lisboa: Edições 70, 1970.

FREUD, Sigmund. Uma Neurose Infantil e Outros Trabalhos. (1918). Edição Standard Brasileira (ESB) das Obras Psicológicas Completas de Sigmund Freud. Vol. VXIII. Rio de Janeiro: Imago, 2006.

O Estranho (1919). In: Edição Standard Brasileira (ESB) das Obras Psicológicas Completas de Sigmund Freud. Vol. XVII. Rio de Janeiro: Imago, 2006.

Inibições, Sintomas e Ansiedade (1926). Edição Standard Brasileira (ESB) das Obras Psicológicas Completas de Sigmund Freud. Vol. VXIII. Rio de Janeiro: Imago, 2006.

HEGEL, George Wilhelm Friedrich. Cursos de estética. São Paulo: Edusp, 2001.

HOFFMANN, Ernst Theodor Amadeus. O Homem de Areia. Rio de Janeiro: Rocco, 2010.

KAFKA, Franz. Um Médico Rural. São Paulo: Companhia das Letras, 2015. Tradução Modesto Carone.

KANT, Inmanuel. Crítica da Faculdade do Juízo. Rio de Janeiro: Forense Universitária, 2012.

KAYSER, Wolfgang. O Grotesco. São Paulo: Perspectiva, 2013.

ROUDINESCO, Elisabeth; PLON, Michel. Dicionário de Psicanálise. Tradução Vera Ribeiro, Lucy Magalhães. Rio de Janeiro: Zahar, 1998. 